\title{
Early family adversity, stability and consistency of institutional care and infant cognitive, language and motor development across the first six months of institutionalization
}

\author{
Joana Baptistaa,b, Jay Belsky c, Sofia Marques ${ }^{d}$, Joana R. Silvab,e, Carla Martins ${ }^{\text {, }}$ \\ Isabel Soares ${ }^{b, *}$ \\ a Instituto Universitário de LISBOA (ISCTE-IUL), Centro de INVESTIGAÇão e Intervenção SOCIAL, LISBOA, PORTUGAL \\ ${ }^{\mathrm{b}}$ CIPsi - Psychology RESEARCH Center, School of Psychology, University of Minho, BRAGA, PORTUGAL

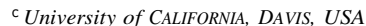 \\ d UNIVERSIDADE LUSíadA, Centro de INVESTIGaÇão em PSICOLOGIA PARA o Desenvolvimento, Porto, PORTUGAL \\ e INPP - PORTUCALENSE Institute for HUMAN Development - Psychology RESEARCH Centre, DEPARTMENT of Psychology AND EDUCATION, \\ University PORTUCALENSE, Porto, PORTUGAL
}

\begin{abstract}
A B S T R A C T
This study extends research on the effects of institutionalization-by examining the trajectories of cognitive, language and motor development of 64 Portuguese infants and toddlers across the first six months of institutionalization, while determining whether pre-institutional adversities and the stability and consistency of institutional care predict children's development. At time of enrollment, $23.4 \%, 32.8 \%$ and $31.3 \%$ of the children were moderately to severely delayed, respectively, in their cognitive, linguistic and motor functioning. Developmental problems persisted after six months of institutionalization. The accumulation of early pre-institutional adversities predicted cognitive and motor limitations at admission to the institutions, but not variation in subsequent development. The stability and consistency of institutional care also failed to predict developmental growth and change. Children who had never lived with their families of origin showed a better language development at enrollment than their counterparts who had lived with their families of origin before institutionalization. Such advantage was followed by a deceleration in language growth after six months of institutional placement. Results are discussed in terms of short- vs. longer-term effects of institutionalization.
\end{abstract}

Keywords: Institutionalization Infant development Early family adversity Stability and consistency of institutional care

\section{Introduction}

Institutional care remains a major intervention worldwide for children whose parents, for a myriad of reasons, cannot guarantee su $\square$ ciently supportive care. Such extensive use of residential institutions occurs despite decades of empirical research documenting the detrimental impact of such early-life experience, at least as all-too-commonly provided, on child development. In fact, a half century of research indicates that children raised in residential institutions are at higher risk for a variety of cognitive and socioemotional developmental problems compared to their never-institutionalized peers (e.g., Van IJzendoorn et al., 2011). On this subject, findings from the Bucharest Early Intervention Program (BEIP) are particularly noteworthy. Young children living in Romanian institutions were randomly assigned to receive care as usual (i.e., continued institutional care) or to be placed in foster care, 
and their development was repeatedly assessed at ages 30, 42 and 54 months, 8 years and 12 years. The cognitive and linguistic functioning of children who remained institutionalized were markedly poorer than that of fellow institutionalized children who were placed in foster care as part of an intervention program. The same was true when the continuously institutionalized children were compared with never-institutionalized age mates (Almas, Degnan, Nelson, Zeanah, \& Fox, 2016; Fox, Almas, Degnan, Nelson, \& Zeanah, 2011; Nelson et al., 2007; Windsor et al., 2011).

Such adverse e $\square$ ects of institutional rearing on cognitive functioning are in line with previously reported meta-analytic findings. Upon combining data from 27 studies, Van IJzendoorn, Luijk, and Ju $\square$ er (2008)) discovered that children with a history of institutional care had compromised scores on tests of intellectual development relative to their family-reared peers; and this was especially so when the former children were exposed to institutional care for long periods of time due to early removal from their families of origin. What remains less explored, despite the evidence just summarized, is whether the developmental limitations of institutionalized children are entirely the result of their exposure to the kind of neglectful care that is characteristic of so many institutions. After all, at least some apparent $\square$ ects of institutional care could result from unmeasured adverse experiences that preceded institutionalization (Van IJzendoorn et al., 2011). Herein we address this issue in a study of 64 institutionalized young Portuguese children, as well as the potential influence of quality of institutional rearing on change in child functioning across the first six months of institutionalization. This will be one of the few existing studies (e.g., Hawk et al., 2018; The St. Petersburg-USA Orphanage Research Team, 2005) aimed to examine the developmental trajectories of very young institutionalized children across their first months of institutional placement, starting from their admission, while also evaluating e $\square$ ects of pre-institutional adversities and quality of institutional care on the development of institutionalized children.

\subsection{PRE-INSTITUTIONALIZATION risks AND their $\mathrm{e} \square$ ects}

The possibility that documented e $\square$ ects of institutional rearing—in observational studies-could be due at least in part to preadmission contextual-developmental risks merits consideration given that most institutionalized children have been exposed to early pre-placement adversities in the family. Indeed, it is not uncommon for institutionalized children to have experienced poor prenatal care and maternal substance use during pregnancy, preterm delivery, family disruption, poverty, malnutrition, and/or maltreatment (Zeanah et al., 2003, Gunnar \& Kertes, 2005). It is well appreciated that these pre-placement adversities pose significant risks for healthy development (e.g., Baptista, Silva, Marques, Martins, \& Soares, 2018; Landgren, Svensson, Strömland, \& Grönlund, 2010; Simmel, 2007). In light of these observations, it seems somewhat surprising that such pre-placement experiences-which can be conceptualized as "selection e $\square$ ects" (into institutionalization)—have not been accounted for in most research on institutional rearing. Routinely, information is missing from case reports on families of origin. When available, such information is often anecdotal in nature and/or is characterized by unknow validity. Thus, much of the (non-experimental, observational) evidence of adverse e $\square$ ects of institutional care on child development has not been well positioned to disentangle e $\square$ ects of institutionalization per se from those of pre-institutional experiences.

To begin to address this lacuna, we examine herein the development trajectories of infants and toddlers across their first six months of institutional placement, beginning with their measured cognitive, language and motor functioning AT time of ADMISSION to these facilities and thus before institutionalization can influence their development. According to a vast amount of empirical evidence, the brain undergoes an impressive amount of change during the opening years of life. Synapses proliferate, connections among brain regions are established, and cortical gray matter develops (Tau \& Peterson, 2010). Well established, as well, is that the early developing brain is especially vulnerable to environmental impoverishment. Research indicates that the early exposure to family and relational adversities, including maltreatment and neglect, may compromise the maturation of several brain structures and functions which, in turn, are linked to the development of early mental abilities (Johnson, 2000; Stamoulis, Vanderwert, Zeanah, Fox, \& Nelson, 2015). Identifying the environmental contributors to healthy cognitive, language and motor functioning in deprived infants and toddlers is thus particularly crucial; this would seem especially so when considering evidence pointing to the important role of early mental abilities in supporting other aspects of development, such as emotional and behavioral functioning (e.g., Olson, Bates, \& Sandy, 2002).

In view of these observations and in line with the cumulative-e $\square$ ects' hypothesis (O'Connor, 2003), also referred to as continuation-of-adversity-hypothesis (Rutter, O'Connor, \& the English and Romanian Adoptees (ERA) Study Team, 2004), we test the proposition that the exposure to pre-institutional adverse experiences will predict children's cognitive, language and motor development, both at time of institutionalization and change that occurs thereafter. According to Rutter (Rutter, 2005) and others (Johnson et al., 2010), the development of children raised in institutions is likely to be influenced by a multitude of factors, including prenatal and neonatal risks and family disruptions. According to these scholars, all such factors should be considered in e $\square$ orts to illuminate influences on compromised development. Thus, within the context of an observational study, we evaluate the anticipated detrimental impact of a set of pre-institutional life conditions, including neonatal and maternal risks, family risks, and child stunted growth, all of which have been previously linked to psychomotor and language delays in young children (Gutbrod, Wolke, Soehne, Ohrt, \& Riegel, 2000). We thus predict that pre-institutional exposure to multiple adversities will prove particularly detrimental for children's cognitive, language and motor development. Given the short-term nature of the longitudinal component of this study, we remain agnostic as to whether pre-institutional risks will forecast change over time in children's functioning while institutionalized.

\subsection{QUALITY of INSTITUTIONAL CARE AND its $\mathrm{e} \square$ ects}

Although we seekto advance understanding of the development of institutionally reared children by investigating e $\square$ ects of pre- 
institutional experience, there is little reason to presume that development is fully shaped by such early exposure. Therefore, we also consider e $\square$ ects of the institutional experience itself, specifically, the quality of institutional daily care, operationalized in terms of the stability and consistency of caregiving. Specifically, we seek to determine whether the institutional experience adds predictive power over and above pre-institutional exposures in predicting change in child functioning over the first six months of institutional placement.

Consideration of e $\square$ ects of the stability and consistency of care would seem particularly important because the quality of institutional care varies greatly (Van IJzendoorn et al., 2011); and this is true even within the same country (e.g., Smyke et al., 2007), including Portugal where the research reported herein was carried out (Baptista et al., 2014). This variation is often a function of a set of organizational constraints, which prevent children from establishing a developmentally facilitative, stable, long-lasting, relationship with a responsive and preferred caregiving figure. Such institutional constraints often include poor caregiver-to-child ratios, frequent changes in caregivers over time, unpredictable caregiving working schedules, and large and heterogeneous groups of children (in terms of age and developmental status).

Prior work indicates that children residing in institutions characterized by deficiencies in the stability of care are at an increased risk of several developmental deficits (e.g., The St. Petersburg-USA Orphanage Research Team, 2008). In this regard, consider the work of Baptista et al. (2014, 2018). These investigators found that very young children residing in institutions characterized by less responsive caregiving presented higher rates of emotional and behavioral problems, compared to their peers living in facilities with higher quality of care. In the same vein, Corval and collaborators (2017) observed that low quality of child-caregiver relationship predicted signs of inhibited attachment disordered behavior. Following this literature, we hypothesize that institutional care will impact children's cognitive, language and motor growth over time; we further hypothesize that the exposure to less stable and consistent caregiving will prove particular detrimental for children's development.

\subsection{The current study}

In Portugal, institutional care remains the major form of alternative care for children abandoned by or taken from their families. Reasons for children being withdrawn from their families and placed in institutions are diverse in Portugal, including physical and emotional neglect, parental psychopathology and substance abuse, family violence, and lack of parental skills. In 2017, almost 8000 children younger than 18 years of age were living in Portuguese residential institutions. The vast majority remained institutionalized for more than one year, with some children experiencing as many as eight years of institutionalization (Instituto de Segurança Social, 2018).

Although Portuguese institutions are characterized by adequate physical resources (e.g., nutrition, medical care), there is, as noted above, great variability in the quality and stability of relational care for the reasons previously outlined (e.g., high child-tocaregiver ratios, frequent changes in caregivers). Notably, institutional caregivers usually do not receive specific training to perform their duties. Perhaps even more significant is that they are often discouraged from forming close and warm relationships with the children in their care (Soares et al., 2004; Baptista et al., 2014).

In the present report we (i) examine the cognitive-, language- and motor-development trajectories of infants and toddlers residing in Portuguese institutions across the first six months of placement, using a growth-curve approach, and (ii) evaluate whether preinstitutional adversities predict children's developmental status at time of placement in the institutions, as well as the subsequent growth. This report also aims (iii) to determine whether the stability and consistency of institutional caregiving accounts for variation in development over time, over and above pre-institutional experiences. Moreover, because children entered the institutions at di $\square$ erent ages and because such variation is linked to compromised functioning in institutionally reared children (Rutter \& English \& Romanian Adoptees Study Team, 2018), age at admission to the institutions is statistically controlled in the current study when evaluating the e ects of pre-and post-institutional enrollment. Whether (or not) the child lived with his/herfamily of origin before institutionalization also served as a covariate in the present study.

\section{Method}

\subsection{PaRTiCipants AND design}

The sample for this study includes 64 children (35 boys, 54.7\%) institutionalized in 18 Portuguese Temporary Care Centers. Inclusion criteria were (i) no disabling genetic syndromes (e.g., Down syndrome) or neurological impairments (e.g., cerebral palsy), (ii) no diagnosis of fetal alcohol syndrome based on child's medical records, and (iii) continued institutionalization for six months following initial placement (see below).

Twenty one children (32.8\%) came to the institutions directly from the maternity ward, having never lived with their family of origin. Among the other children, $15(34.1 \%)$ were no older than six months when institutionalized; $16(36.4 \%)$ were 7 to 12 months old, and the remaining $(n=13,29.5 \%)$ were between 13 and 26 months old. The reasons why children were placed in the institutions varied, including neglect $(n=24,37.5 \%)$, physical $(n=2,2.9 \%)$ and sexual $(n=2,2.9 \%)$ abuse, abandonment $(n=12$, $18.8 \%)$, lack of parental skills $(n=38,59.4 \%)$, severely limited socioeconomic resources $(n=18,28.1 \%)$, parental psychopathology/intellectual disability $(n=24,37.5 \%)$, and family violence $(n=18,28.1 \%)$; percentages do not sum to $100 \%$ because in some cases there were multiple reasons for institutional placement.

This research project was approved by Portuguese Social Services and the Portuguese National Commission for Data Protection. Whereas the first entity is responsible for managing the institutions and is the legal guardian of children while they remain there, the 
second is responsible for the protection of human participants in research carried out in Portugal. After approval by the two entities, the study was presented to the sta $\square$ at each institution, and written informed consents were obtained from the biological parents or child's legal guardian (in the case of children who have been abandoned or were leaving the institutions for adoption), and from the institution director and caregivers. All assessments were conducted at the institutional settings.

\subsection{Procedures AND MEASURES}

Predictor constructs are delineated first, followed by the measured outcomes. The date of admission and the birth date of the child were obtained from records maintained at the institution, enabling us to calculate the age at time of admission to the institutions. Age at admission, as well as whether (or not) the child lived with his/her family of origin before institutionalization, served as covariates in the prediction analysis.

\subsubsection{CUMULATIVE PRE-INSTITUTIONAL ADVERSE experiences}

A socio-demographic questionnaire was completed based on information in the children's files at the institutions. An early-life risk composite was based on 13 risk factors selected on the basis of previous research (Gutbrod et al., 2000; Laucht, Esser, \& Schmidt, 1997; Soares et al., 2004): (1) maternal physical disease (e.g., AIDS, hepatitis; 23.4\%); (2) maternal substance abuse during pregnancy $(25 \%)$; (3) medical determination of high-risk gestation $(39.1 \%) ;(4)$ maternal psychopathology $(21.9 \%)$; (5) maternal intellectual disability $(17.2 \%)$; (6) child premature birth (<37 gestational weeks, $23.4 \%)$; (7) low birth weight $(<2.500 \mathrm{~g}, 21.9 \%) ;(8)$ domestic violence (involving any household members, 28.1\%); (9) prior at-risk determination of the family by social workers (based on conditions such as maltreatment, neglect or abandonment of other children; 62.5\%); (10) previous institutionalization/adoption of child's sibling (48.4\%); (11) parental neglect as reason for institutionalization (46.9\%); (12) prostitution by mother ( $21.9 \%)$; and, finally, (13) child stunted growth at admission to the institution, serving as a proxy for undernutrition. Stunted growth was defined as height-for-age less than -2 SD. Height (supine length $<24$ months or standing height $\geq 24$ months) was measured at admission and converted intoz-scores using WHO AnthroStatistical Software, a $\square$ ording unbiased comparison of children ofdi $\square$ erentages. In the present sample, $26.6 \%(n=17)$ of children were stunted at admission.

Each individual risk was scored as 0 ("absent") or 1 ("present"). Items were then summed and the cumulative score was divided by the number of available variables. All children had a minimum of $75 \%$ of variables (see Table 1 ). Therefore, the resulting composite risk score represents the proportion of items on which the child received a score of 1 , with higher scores reflecting greater early adversity.

Table 1

Descriptive Statistics for Study Variables.

\begin{tabular}{|c|c|c|c|c|}
\hline & $n$ & $M$ & $S D$ & Min-Max \\
\hline Age at admission to the institution (months) & 64 & 7.12 & 7.28 & $0-26$ \\
\hline Bayley-III cognitive score TO & 64 & 88.47 & 18.21 & $9-120$ \\
\hline Bayley-III language score T0 & 64 & 86.62 & 14.54 & $47-115$ \\
\hline Bayley-III motor score T0 & 64 & 88.13 & 15.49 & $55-127$ \\
\hline Bayley-III cognitive score T1 & 64 & 92.19 & 12.56 & $55-115$ \\
\hline Bayley-III language score T1 & 64 & 88.47 & 13.26 & $56-109$ \\
\hline Bayley-III motor score T1 & 64 & 91.38 & 15.61 & $55-130$ \\
\hline Bayley-III cognitive score T2 & 64 & 90.55 & 11.62 & $55-110$ \\
\hline Bayley-III language score T2 & 64 & 87.42 & 12.65 & $56-118$ \\
\hline Bayley-III motor score T2 & 64 & 88.61 & 16.39 & $52-121$ \\
\hline Early pre-institutional risks (composite) & 64 & 3.34 & 1.99 & $0-9$ \\
\hline Stability and consistency of institutional care & 64 & 15.18 & 4.25 & $8-25$ \\
\hline Gender, girls & 64 & 35 & 54.7 & \\
\hline \multicolumn{5}{|l|}{ Pre-institutional risk factors, present } \\
\hline Maternal physical disease & 61 & 15 & 23.4 & \\
\hline Maternal substance abuse during pregnancy & 58 & 16 & 25 & \\
\hline Medical determination of high-risk gestation & 64 & 25 & 39.1 & \\
\hline Maternal psychopathology & 61 & 14 & 21.9 & \\
\hline Maternal intellectual disability & 61 & 11 & 17.2 & \\
\hline Premature birth & 63 & 15 & 23.4 & \\
\hline Low birth weight & 62 & 14 & 21.9 & \\
\hline Domestic violence & 64 & 18 & 26.1 & \\
\hline Prior evaluation of the family by social workers & 64 & 40 & 62.5 & \\
\hline Previous institutionalization/adoption of sibling & 61 & 31 & 48.4 & \\
\hline Parental neglect & 64 & 30 & 46.9 & \\
\hline Prostitution by mother & 59 & 14 & 21.9 & \\
\hline Stunted growth & 64 & 17 & 26.6 & \\
\hline
\end{tabular}

Note T0 $=$ Time 0 or admission to the institution, $\mathrm{T} 1=$ Time 1 or 3 months of institutionalization, $\mathrm{T} 2=$ Time 2 or 6 months of institutionalization 


\subsubsection{STABILITY AND consistency of INSTITUTIONAL CARE}

An observational measure developed specifically for the current research, Assessment of the Quality of Institutional Care (Silva et al. , 2010), which includes a scale reflecting the stability and consistency of caregiving, was used. The AQIC evaluates structural and relational aspects of the quality of institutional care, based on extensive observations made by highly trained observers across the entire six-month period. Because institutions varied greatly in their practices across days of the week and periods of the day, a minimum of $30 \mathrm{~h}$ of observation were conducted at each institution. Observations were made on di $\square$ erent days, during daily interactions and routines (e.g., eating, bathing, free time). The AQIC was used in previous research with institutionalized young children (for a detailed description, see Baptista et al., 2014).

The scale measuring stability and consistency of caregiving is composed by six items, rated on a 5-point scale (1-never present, 3sometimes/somewhat, 5 -always present), assessing (1) the quality of the caregiving environment in terms of the adequacy of daily child-to-caregiver ratio; (2) number of caregivers; (3) format of work shifts, from fixed to rotating; (4) predictability of the working shifts; (5) employee turnover; and (6) continuity of care, operationalized in terms of the stability of children within the groups. With regard to the last item, then, groups were judged unstable when there were multiple changes in child membership. A total quality-ofcare score was calculated by summing ratings across items. Higher scores reflected greater caregiving stability. Intraclass correlation for intercoder reliability was 0.83 , calculated for 8 of the 18 participating institutions. For the present study, the internal consistency of the stability-and-consistency-of-caregiving scale proved to be more than adequate, with a coe $\square$ cient alpha of 0.74 .

\subsubsection{Cognitive, LANGUAGE AND motor development}

Children's mental development was assessed using a translated Portuguese version of the Bayley Scales of Infant and Toddler Development, Third Edition (BSID-III; Bayley, 2006), when children arrived at the institutions (TO, $M=7.12$ months old, $S D=7.28$, range $0-26$ ) and three and six months later ( $\mathrm{T} 1, M=9.45$ months old, $S D=7.25$, range 2-27; and T2, $M=12.33$ months old, $S D=7.23$, range 5-31, respectively). The BSID-III is an individually administered measure, valid for children up to 42 months of age. It includes three sub-scales for the assessment of child cognitive, language, and motor development. The cognitive sub-scale assesses exploration and manipulation, sensorimotor development, and object relatedness, among other areas. The language sub-scale covers two areas of functioning, namely, receptive and expressive communication. Finally, the motor sub-scale covers both fine-motor and gross-motor capabilities. A summed raw score is computed and the composite scores are determined for each sub-scale. The BSID-III was administered by highly trained psychologists.

\subsection{ANALYTIC PLAN}

Descriptive and correlational analyses were, first, performed. Then, a longitudinal mixed model approach was employed using maximum likelihood (ML) estimation; it was applied, separately, to each dependent construct (i.e., mental, language, motor functioning), following a two-step strategy (Singer \& Willet, 2003). In a first step, unconditional models were evaluated, and cognitive, language and motor trajectories were examined, using time as the only predictor. This approach provides an indication of the average level of cognitive, language and motor functioning at TO (i.e., the intercept), and the mean linear and quadratic changes over the first six months of institutionalization (i.e., slopes). For each dimension of child development (i.e., cognitive, language and motor), two polynomial functions were fitted to describe longitudinal changes: a linear (or first-order; the rate of growth systematically increases or decreases over time) and a quadratic (or second-order; the slope accelerates/decelerates over time) curve. Comparisons across polynomials were based on the di $\square$ erences in -2 LL between models, using a chi-square likelihood ratio test.

In the second step, conditional or predictive models were computed, separately for each dependent construct (i.e., cognitive, language and motor functioning). This time the first model included the pre-institutional risk composite as predictor. The second model included this variable and the stability and consistency of institutional care. These conditional models, respectively, (i) estimated e $\square$ ects of pre-institutional experiences on cognitive, language and motor development at T0 and over time, and (ii) whether the stability and consistency of institutional care contributed to the prediction of child development over and above pre-institutional factors. Covariates (i.e., child age at admission and whether or not the child lived with his/her family of origin before institutionalization) were also considered. All independent variables were centered at the grand mean (i.e., the overall mean was subtracted from the individual value of each child for each predictor). The baseline or T0 intercept and linear and quadratic slopes were allowed to vary across individuals. The covariance matrix was unstructured, as this significantly improved the fit of the models.

\section{Results}

Descriptive statistics are presented in Table 1. At admission to the institutions (T0), $23.4 \%, 32.8 \%$ and $31.3 \%$ of children had Bayley-III cognitive, language and motor score below 80 , respectively. At T1, $18.8 \%, 29.7 \%$ and $21.9 \%$ of children scored below 80 on the respective cognitive, language and motor sub-scales. Finally, by the end of six months of institutionalization (T2), 17.2\%, $26.6 \%$ and $31.3 \%$ of children had, respectively, cognitive, language and motor scores below 80 , respectively.

\subsection{UNCONDITIONAL models}

Longitudinal mixed models examining the cognitive, language and motor trajectories were performed, considering the three time points. Results of the unconditional models are presented in Table 2. On the cognitive and language sub-scales, estimates of fixed e $\square$ ects indicated that both the linear AND quadratic trends were non-significant, despite the apparent changes in raw percentages 
Table 2

Growth Curve Models of Child Cognitive, Language and Motor Development across the First Six months of Institutional Placement.

\begin{tabular}{|c|c|c|c|}
\hline & Cognitive Development & Language Development & Motor Development \\
\hline & $\beta$ estimate (SE) & $\beta$ estimate (SE) & $\beta$ estimate (SE) \\
\hline Intercept & $32.12(2.99)^{* * *}$ & $25.51(2.89)^{* * *}$ & $29.50(3.26)^{* * *}$ \\
\hline Time & $7.69(6.03)$ & $5.47(4.30)$ & $11.07(5.12)^{*}$ \\
\hline Time $^{2}$ & $-3.78(2.86)$ & $-2.82(2.01)$ & $-5.02(2.38)^{*}$ \\
\hline Early pre-institutional risks & $48.05(18.76)^{*}$ & $-28.29(18.46)$ & $42.17(20.76)^{*}$ \\
\hline Time $x$ Early pre-institutional risks & $-35.73(39.37)$ & $-16.94(27.02)$ & $-24.39(33.48)$ \\
\hline Time $^{2} \times$ Early pre-institutional risks & $3.21(18.76)$ & $14.06(13.03)$ & $6.41(15.55)$ \\
\hline Stability and consistency of institutional care & $-.81(.67)$ & $-.64(.66)$ & $-.31(.75)$ \\
\hline Time $\times$ Stability and consistency of care & $.67(1.43)$ & $.44(1.01)$ & $1.07(1.21)$ \\
\hline Time $^{2} \times$ Stability and consistency of care & $-.15(.68)$ & $.15(.47)$ & $-.60(.56)$ \\
\hline Log Likelihood & 1730.014 & 1672.520 & 1746.364 \\
\hline AIC & 1756.014 & 1698.520 & 1772.364 \\
\hline BIC & 1798.362 & 1740.868 & 1814.712 \\
\hline
\end{tabular}

$*_{p}<.05$.

$* * p<.01$

$* * * p<.001$.

listed above. Regarding motor development, however, data showed that both the linear $(F(1,64)=4.68, p=0.033)$ and the quadratic trend $(F(1,64)=4.47, p=0.038)$ significantly described the pattern of data. Adding the second-order (quadratic) polynomial improved the fit of the model $\left(\mathrm{x}^{2}(1)=4.32, p<.05\right)$. Therefore, the quadratic trend was judged to best describe the pattern of motor development over time, indicating that rate of growth increased over the first three months of institutional placement, followed by a deceleration thereafter.

Random parameters of the models were examined next. The variance around the intercept proved significant for all three outcomes, thus documenting individual variability in the cognitive $(p=.039)$, language $(p<.001)$, and motor $(p<.001)$ functioning at time of admission to the institutions. The covariance between the slope and intercept proved significant and positive for motor development $(p=.029)$, suggesting that children with better initial Bayley-III motor scores experienced a more rapid and positive change in this domain of functioning. The variance around the slope proved non-significant for all developmental domains; thus, individual variability in the rate of change, over the first six months of institutionalization, was not significant.

\subsection{CONDITIONAL models}

Even though prior analyses revealed non-significant individual variability in the growth parameters, three conditional models were computed, one for each of the three outcomes. We proceeded this way because descriptive statistics (see Table 1) suggested that children appeared to di $\square$ er in their cognitive, language and motor profiles at admission to the institutions, as well as in subsequent assessment moments. The fact that our sample was small in size further suggested that embracing a null finding as a guide to subsequent model testing was questionable.

The first models were performed entering early pre-institutional risks as predictors. Results indicated that pre-institutional risks significantly forecasted child cognitive and motor functioning at entry to the institutions: children exposed to more (cumulative) preinstitutional risks evinced poorer cognitive (T0: $\beta=48.05, p=0.012$ ) and poorer motor (T0: $\beta=42.17, p=0.046$ ) development than other children at the time of institutional placement. This was not the case, however, for linguistic functioning. Likewise, preinstitutional risks did not forecast cognitive, language or motor developmental changes over time (see Table 2).

The above results were obtained even when all three conditional models (i.e., for cognitive, language and motor functioning) were repeated, controlling for child age at admission and whether (or not) the child lived with the family of origin before institutionalization. To be noted that child age at admission to the institutions proved unrelated to cognitive, language or motor development in all the models. However, results indicated that living (or not) with the biological family predicted child language at enrollment, but not cognitive or motor functioning: children who had not lived with their families of origin prior to institutionalization displayed a better language development (T0: $\beta=7.77, p=0.042$ ) than did those who had lived with their families of origin. Moreover, living (or not) with the biological family predicted linguistic changes over time, but not cognitive or motor functioning, in a manner more consistent with a quadratic trend $(F(1,64)=5.98, p=0.004)$. Analyses indicated that the rate of linguistic and motor growth increased over the first three months of institutional placement, followed by a deceleration thereafter, but only among children who had never lived with their families of origin. These children showed a better linguistic performance than those who had lived with their families of origin both at T0 and T1 (all $p<0.05$; see Table 3 ). No significant differences 


\begin{tabular}{|c|c|c|c|c|c|}
\hline & \multicolumn{4}{|c|}{ Family Living Status } & \multirow[t]{3}{*}{ Etest } \\
\hline & \multicolumn{2}{|c|}{$\begin{array}{l}\text { Lived with the fanily } \\
\text { before instinurionalteation }(n=43)\end{array}$} & \multicolumn{2}{|c|}{$\begin{array}{l}\text { Did not Ived with the farily } \\
\text { before instrutionalizarion }(n=21)\end{array}$} & \\
\hline & M & $S D$ & M & $S D$ & \\
\hline Bayley-III cognitive score To & 87.60 & 20.65 & 90.24 & 11.99 & .54 \\
\hline Bayley-IIl language score To & 83.84 & 13.45 & 92.33 & 15.34 & $2.27^{*}$ \\
\hline Bayley-III motor score T0 & 87.02 & 17.63 & 90.38 & 9.76 & .81 \\
\hline Bayley-III cognitive score T1 & 92,44 & 12.22 & 91.66 & 13.54 & -.23 \\
\hline Bayley-III language score T1 & 84.44 & 11.61 & 96.71 & 12.82 & $3.84^{\star \star * *}$ \\
\hline Bayley-III motor score T1 & 89.16 & 17.04 & 95.90 & 11.24 & 1.64 \\
\hline Bayley-IIl cognitive score T2 & 90.00 & 11.44 & 91.67 & 12,18 & .54 \\
\hline Bayley-III language scone T2 & 87.05 & 13.06 & 88.19 & 12.04 & 34 \\
\hline Bayley-III motor score T2 & 90.28 & 17.10 & 85.19 & 14.63 & -1.17 \\
\hline
\end{tabular}

emerged, however, between groups at T2.

The three conditional models were repeated, considering now both pre-institutional risks AND the stability and consistency of institutional care as predictors. These models tested the contribution of both independent variables to cognitive, language and motor functioning. It thus $a \square$ orded determination of whether the stability and consistency of institutional caregiving contributed to children's development over and above pre-institutional experiences. In accordance with the first conditional model, results indicated, once again, that more pre-institutional risks forecast poorer cognitive (T0: $\beta=50.30, p=0.009$ ) and poorer motor (T0: $\beta=43.05, p$ $=0.043$ ) functioning at entry to the institutions, but not language development at enrollment, or any developmental changes over time. The stability and consistency of institutional care did not predict changes in cognitive, language or motor development across the first six months of institutionalization, as revealed by log-likelihood tests (all $p>.05$ ) (see Table 2 ).

Then, the three conditional models (i.e., for cognitive, language and motor functioning) were repeated, controlling, once again, for child age at admission and whether (or not) the child lived with his/her family of origin before institutionalization. The same results were obtained for all models. Living (or not) with the biological family, but not age at admission, predicted child language at enrollment (T0: $\beta=7.61, p=0.004$ ), as well as linguistic changes over time, again in a manner more consistent with a quadratic trend $(F(1,64)=11.90, p=0.001)$.

\section{Discussion}

The current report extends research on the e $\square$ ects of institutionalization by examining cognitive, language and motor development at time of institutional enrollment and across the first six months of institutional placement in order to (i) evaluate whether early pre-institutional adversities contribute to child developmental status at admission and/or (ii) to the subsequent pattern of growth; and (iii) whether, most originally, the stability and consistency of institutional care increased prediction of change in cognitive, language and motor development over and above pre-enrollment adversities, all while controlling for age of enrollment and whether (or not) the child lived with his/her family of origin before institutionalization.

Recall that more than $20 \%$ of the children were moderately to severely delayed in their cognitive, language and motor development at admission to the institutions. Data also revealed developmental stability over time in that after six months of institutionalization a substantial number of children continued to show limited cognitive, linguistic and motor capabilities. Then, there was the fact that longitudinal modeling failed to document any significant linear or quadratic change in cognitive or language scores over the first six months of institutional placement. Notably, however, a quadratic pattern of growth characterized motor development, revealing an initial increase in the rate of motor growth, followed by a deceleration by the time children had been institutionalized for six months. These results add to the existing literature by suggesting that residential care does not o $\square$ er the necessary conditions for the child to move from a pre-existing negative developmental pathway to a more adaptive (or, at least, a benign) one, at least not within the first six months of institutionalization in the Portuguese settings that were the focus of this report. Also somewhat surprising was the failure to discern significant variability across children in rate of developmental growth over the first six months of institutional placement. This could be due to the fact that a period of six months may be insu $\square$ cient to produce variable developmental changes, especially since there is much heterogeneity in the rate of psychomotor growth during infancy and toddlerhood (e.g., Kieviet, Piek, Aarnoudse-Moens, \& Oosterlaan, 2009). Developmental changes may become more evident over a longer period of time, or already occurring but at a steady rate slower than typical.

Consistent with the cumulative-e $\square$ ects' hypothesis (O'Connor, 2003), as well as with previous findings (Gunnar \& Kertes, 2005; Soares et al., 2004; Zeanah et al., 2003) and our expectations, children exposed to more adverse pre-institutional experiences evinced poorer cognitive and motor development at time of admission to the institutions. Such evidence underscores the detrimental impact of early adverse (non-institutional) experiences on child development. Surprisingly, though, early pre-institutional factors did not 
predict language scores at enrollment. It may well be the case that other family processes, including social relational ones, would be better at explaining individual di $\square$ erences in language functioning at such early ages. In line with this claim is evidence that parental sca $\square$ olding, sensitivity and engagement, as well as time spent in one-to-one interactions, are more predictive of early language development than sociodemographic factors of the kind we were positioned to include in this study (Miquelote, Santos, Caçola, Montebelo, \& Gabbard, 2012; Tamis-LeMonda, Shannon, Cabrera, \& Lamb, 2004). It should also be considered that the impact of preinstitutional adverse experiences on language development may become evident only after a longer period of institutional placement. Biological risk factors may also be important in accounting for the initial individual variability in language functioning, including specific prenatal experiences and their neurological sequelae that our measurements did not capture.

Interestingly, and despite the above possibilities, results indicated that children who had never lived with theirfamilies of origin before institutionalization showed better language abilities at enrollment than their peers who had lived with their families. This is not surprising. After all, it is well documented the detrimental impact of child abuse and neglect (i.e., the kind of experience most children who had lived with their families have been exposed to) on language development (Sylvestre, Bussiéres, \& Bouchard, 2016). Somewhat surprising, however, is the result revealing a quadratic pattern of developmental change among children who had never lived with their families of origin before institutionalization, characterized by a deceleration in the rate of language growth by the time children had been in residential care for six months. The apparent developmental advantage evinced by children who have never lived with their families of origin seems to have disappeared, as these children no longer presented significantly better language abilities aftersixmonths of institutionalization, compared to theirpeers whohavelived with theirfamilies. These findingsare in line with research carried out with post institutionalized Romanian children showing that six or more months of institutional placement is related to short and long-term developmental problems in young children (Kumsta et al., 2017; Rutter, Kumsta, Schlotz, \& SonugaBarke, 2012). Such proximity of results should be analyzed with caution, however. Afterall, the present study pertains to young children placed in institutions in Western Europe, making the psychosocial care environment potentially di $\square$ erent from many of the studies of institutional rearing in EasternEurope.

Perhaps our most notable result, especially given our unique position to address the issue, was that neither the pre-institutional experiences nor the stability and consistency of institutional care significantly predicted developmental change in cognition and/or language. To be noted, however, is that these non-results pertaining to e $\square$ ects of quality-of-care are in line with previous findings (that do not reflect controls for pre-institutional experiences) and with claims that even institutions which provide more stable and consistentcare than many others do still do noto $\square$ ersu $\square$ ciently supportive careto promote child well-being (Van IJzendoorn etal., 2011). Even when some residential settings provide adequate nutrition and health care for the child, as appears to be the case with Portuguese institutions, the institutions studied remain limited as environments for promoting healthy development (e.g., via developmentally appropriate interactions with a caring adult). This is likely due to those structural constraints highlighted in the Introduction (e.g., poor caregiver-to-child ratios, high sta $\square$ turnover), as well as limited sta $\square$ training and discouragement from forming any type of emotional bond with the child (The St. Petersburg-USA Orphanage Research Team, 2008; Vorria, Rutter, Pickles, Wolkind, \& Hobsbaum, 1998). Even the highest levels of institutional stability and consistency observed in this inquiry may simply have been insu $\square$ cient to promote developmental change and growth. In addition, it should not be ruled out the possibility that other institutional factors are more important than the consistency and stability of care in determining the cognitive, language and motor development trajectories of institutionalized infants and toddlers. As showed in previous research, caregivers' responsiveness may be one of such factors. For example, in an intervention study carried out with young children living in Russian institutions, caregiver sensitivity was found to be more beneficial for child cognitive development during the first year of institutionalization than the consistency of care (Hawk et al., 2018)

In light of the null findings involving both pre-institutional and quality-of-care factors when it came to predicting change in cognitive and language development, it seems noteworthy that a significant association emerged between the intercept and slope for motor development. Perhaps better motor skills at enrollment, which recall were predicted by fewer pre-institutional risks, could serve as a protective factor, making children more capable of taking advantage of the environmental opportunities (even if minimal) o $\square$ ered by the institutions. In fact, it should not be ruled out that institutional caregivers may have been more responsive to those children who were more able, due to their greater motor skills, to signal their needs and interests. Whether (or not) such interactive processes are contributing to changes in motor development among institutionalized infants and toddlers is something to be clarified by future research.

The fact that this report focused on only the first six months of institutionalization and was modest in terms of sample size means that it would be problematical to over-generalize its results. It is quite conceivably that variation in cognitive, language and motor growth could emerge after six months of institutional placement, as suggested above. Likewise, the e $\square$ ects of pre-institutional adversities and especially the stability and consistency of institutional care could increase over time, perhaps as the latter begins to accumulate. Future work should address these issues. Indeed, one question meriting attention is why pre-institutional factors predict development at institutional admission but not development thereafter. Could this indicate that the institutions are "erasing" e $\square$ ects of experiences and exposures prior to admission? And, if so, is such a process beneficial, ameliorating deficits of those functioning most poorly when admitted, or detrimental, by undermining the development of those functioning best at admission?

It will also be important for future research to illuminate whether the two sets of predictive factors examined herein-preinstitutional adversities and the stability and consistency of institutional care-interact in predicting cognitive, language and motor trajectories, over six and more months of institutional placement. It is imaginable, after all, that the quality of care could attenuate-or amplify-the e $\square$ ects of pre-institutional experiences; and, if so, this could have implications for whether-and how-institutions could or should treat children di $\square$ erently. Sample size limitations precluded us from addressing this issue in the current 
inquiry. Another goal of future work should be to unpack composite indices of the early risk in order to determine which particular experiences and exposures might contribute most to the development of institutional children's development. Larger samples will be required for that. At the same time, future work should expand upon our list of pre-institutional and quality-of-care predictors when trying to illuminate determinants of children's functioning at time of institutional admission and development while institutionalized. Finally, although the BSID-III is the most widely used development assessment tool for very young children worldwide, less is known about its psychometric properties and feasibility in Portugal. Thereby, caution is needed in the interpretation of the present results. Despite the sample-size, measurement and temporal limitations of our work, the findings presented have important implications for practice. Most notably, given that there are currently around 8000 institutionalized children in Portugal (Instituto de Segurança Social, 2018), and that years of research have documented the negative impact of such early-life experience on child development (e.g., Van IJzendoorn et al., 2008, 2011), the replacement of institutional care with (well-supported) foster families is an urgent need in this country. In fact, there are theoretical and empirical reasons to believe that high quality foster families would better serve the needs of disadvantaged young children by, among other things, increasing the stability and consistency of care received (Fox et al., 2011; Nelson et al., 2007; Windsor et al., 2011). E $\square$ orts should also be made to improve the quality of parental care of expectant, atrisk parents, so that children do not need to be placed in institutions in the first place.

\section{References}

Almas, A., Degnan, K., Nelson, C. A., Zeanah, C. H., \& Fox, N. A. (2016). IQ at age 12 following a history of institutional care: Findings from the Bucharest Early Intervention Project. DEVELOPMENTAL Psychology, 52(11), 1858-1866. https://doi.org/10.1037/dev0000167.

Baptista, J., Belsky, J., Marques, S., Silva, J., Oliveira, P., Mesquita, A., ... Soares, I. (2014). The interactive e $\square$ ect of maltreatment in the family and unstable institutional caregiving in predicting behavior problems in toddlers. Child Abuse \& Neglect, 38, 2072-2079. https://doi.org/10.1016/j.chiabu.2014.10.05.

Baptista, J., Silva, J., Marques, J., Martins, C., \& Soares, I. (2018). Early maltreatment and current quality of relational care predict socioemotional problems among institutionalized infants and toddlers. INFANT MENTAL HEALTH JOURNAL, 39(6), 718-729. https://doi.org/10.1002/imhj.21741.

Bayley, N. (2006). BAYLEY SCALES of INFANT AND toddler development (Third edition). San Antonio, TX: Harcourt Assessment.

Fox, N., Almas, A., Degnan, K., Nelson, C. A., \& Zeanah, C. H. (2011). The e $\square$ ects of severe psychosocial deprivation and foster care intervention on cognitive development at 8 years of age: Findings from the Bucharest Early Intervention Project. JOURNAL of Child Psychology AND PSYCHIATRY, 52(9), 919-928. https://doi.org/ $10.1111 / \mathrm{j} .1469-7610.2010 .02355 . x$

Gunnar, M., \& Kertes, D. (2005). Prenatal and postnatal risks to neurobiological development in internationally adopted children. In D. Brodzinsky, \& J. Palacios (Eds.). PSYCHOLOGICAL issues in ADOPTION (pp. 47-66). London: Praeger.

Gutbrod, T., Wolke, D., Soehne, B., Ohrt, B., \& Riegel, K. (2000). E $\square$ ects of gestation and birth weight on the growth and development of very low birthweight small for gestational age infants: A matched group comparison. Archives of DISEASE in Childhood FETAL AND NEONATAL, 82, F208-F214.

Hawk, B., McCall, R., Groark, C., Muhamedrahimov, R. J., Palmov, O., \& Nikiforova, N. (2018). Caregiver sensitivity and consistency and children's prior family experience as contexts for early development within institutions. INFANT MENTAL HEALTH JOURNAL, 39(4), 432-448. https://doi.org/10.1002/imhj.21721.

Instituto de Segurança Social (2018). CASA 2017: RELATÓRIO de CARACTERIZAÇão ANUAL DA SITUAÇão de ACOLHIMENTO DAS CRIANCAS e jovens [CASA 2017: Report of the ANNUAL CHARACTERIZATION of INSTITUTIONAL CARE of children AND young people] [ISS, IP Web site]Available at: http://www.seg-social.pt/documents/10152/16000247/Relatorio_ CASA_2017/537a3a78-6992-4f9d-b7a7-5b71eb6c41d9. (Accessed March 29, 2019).

Johnson, D., Guthrie, D., Smyke, A. T., Koga, S. F., Fox, N. A., Zeanah, C. H., \& Nelson, C. A. (2010). Growth and associations between auxology, caregiving environment, and cognition in socially deprived Romanian children randomized to foster vs. Ongoing institutional care. Archives of PEDIATRICS \& Adolescent Medicine, 164, 507-516.

Johnson, M. H. (2000). Functional brain development in infants: Elements of an interactive specialization framework. Child Development, 1, 75-81.

Kieviet, J., Piek, J., Aarnoudse-Moens, C. S., \& Oosterlaan, J. (2009). Motor development in very preterm and very low-birth weight children from birth to adolescence: A meta-analysis. JAMA, 302, 2235-2242. https://doi.org/10.1001/jama.2009.1708.

Kumsta, R., Schlotz, W., Golm, D., Moser, D., Kennedy, M., Knights, N., ... Sonuga-Barke, E. (2017). HPA axis dysregulation in adult adoptees twenty years after severe institutional deprivation in childhood. Psychoneuroendocrinology, 86, 196-202. https://doi.org/10.1016/j.psyneuen.2017.09.021.

Landgren, M., Svensson, L., Strömland, K., \& Grönlund, A. (2010). Prenatal alcohol exposure and neurodevelopmental disorders in children adopted from Eastern Europe. PEDIATRICS, 125, 1178-1185. https://doi.org/10.1542/peds.2009-0712.

Laucht, M., Esser, G., \& Schmidt, M. (1997). Developmental outcome of infants born with biological and psychosocial risks. JOURNAL of Child Psychology AND PSYCHIATRY, $38,843-853$.

Miquelote, A. F., Santos, D. C. C., Caçola, P. M., Montebelo, M. I., \& Gabbard, C. (2012). E $\square$ ect of the home environment on motor and cognitive behavior of infants. INFANT BEHAVIOR \& Development, 35, 329-334. https://doi.org/10.1016/j.infbeh.2012.02.002.

Nelson, C. A., Zeanah, C. H., Fox, N. A., Marshall,P. J., Smyke, A.T., \& Guthrie, D. (2007). Cognitive recovery in socially deprived young children: The Bucharest early intervention project. Science, 318(5858), 1937-1940. https://doi.org/10.1126/science.1143921.

O'Connor, T. (2003). Early experiences and psychological development: Conceptual questions, empirical illustrations, and implications for intervention. Development AND PSYCHOPATHOLOGY, 15, 671-690.

Olson, S., Bates, J., Sandy, J., et al. (2002). Early developmental precursors of impulsive and inattentive behavior: From infancy to middle childhood. JouRNAL of Child Psychology AND PSYCHIATRY, 43, 435-447.

Rutter, M. (2005). Adverse preadoption experiences and psychological outcomes. In D. Brodzinsky, \& J. Palacios (Eds.). PSYCHOLOGICAL isSues in ADOPTION. London: Praeger.

Rutter, M., \& English and Romanian Adoptees Study Team (2018). Developmental catch-up, and deficit, following adoption after severe global early privation. JOURNAL of Child Psychology AND PSYCHIATRY, 39, 465-476.

Rutter, M., Kumsta, R., Schlotz, W., \& Sonuga-Barke, E. (2012). Longitudinal studies using a "natural experiment" design: The case of adoptees from Romanian institutions. JOURNAL of the AMERICAN ACADEMY of Child AND Adolescent PSYCHIATRY, 51(8), 762-770. https://doi.org/10.1016/j.jaac.2012.05.011. 
Rutter, M., O'Connor, T. G., \& the English and Romanian Adoptees (ERA) Study Team (2004). Are there biological programming e $\square$ ects for psychological development? Findings from a study of Romanian adoptees. DEVELOPMENTAL Psychology, 40, 81-94.

Silva, J., Baptista, J., Marques, S., Oliveira, P., Oliveira, A., \& Soares, I. (2010). Assessment of the QUALITY of INSTITUTIONAL CARE. Unpublished manuscriptBraga: University of Minho.

Simmel, C. (2007). Risk and protective factors contributing to the longitudinal psychosocial well-being of adopted foster children. JOURNAL of EMOTIONAL AND BEHAVIORAL Disorders, 15, 237-249. https://doi.org/10.1177/10634266070150040501.

Singer, J., \& Willet, J. (2003). Applied LONGITUDINAL DATA ANALYSIS. NY: Oxford University Press.

Smyke, A. T., Koga, S., Johnson, D., Fox, N. A., Marshall, P. J., Nelson, C. A., \& BEIP Core Group (2007). The caregiving context in institution reared and family reared infants and toddlers in Romania. JOURNAL of Child Psychology AND PSYCHIATRY, 48, 210-218.

Soares, I., Belsky, J., Oliveira, P., Silva, J., Marques, S., Baptista, J., \& Martins, C. (2004). Does early family risk and current quality of care predict indiscriminate behavior in institutionalized Portuguese children? ATTACHMENT \& HUMAN Development, 16, 137-148. https://doi.org/10.1080/14616734.2013.869237.

Stamoulis, C., Vanderwert, R., Zeanah, C. H., Fox, N. A., \& Nelson, C. A. (2015). Early psychosocial neglect adversely impacts developmental trajectories of brain oscillations and their interactions. JOURNAL of Cognitive Neuroscience, 27, 2512-2528. https://doi.org/10.1162/jocn a 00877.

Sylvestre, A., Bussiéres, E., \& Bouchard, C. (2016). Language problems among abused and neglected children: A meta-analytic review. Child MALTREATMENT, 21(1), 47-58. https://doi.org/10.1177/1077559515616703.

Tamis-LeMonda, C., Shannon, J., Cabrera, N., \& Lamb, M. E. (2004). Fathers and mothers at play with their 2- and 3-year-olds: Contributions to language and cognitive development. Child Development, 75, 1806-1820.

Tau, G., \& Peterson, B. S. (2010). Normal development of brain circuits. NEUROPSYCHOPHARMACOLOGY, 35, 147-168. https://doi.org/10.1038/npp.2009.115.

The St. Petersburg-USA Orphanage Research Team (2005). Characteristics of children, caregivers, and orphanages for young children in St. Petersburg, Russian Federation. JOURNAL of Applied DEVELOPMENTAL Psychology, 26(5), 477-506. https://doi.org/10.1016/j.appdev.2005.06.002.

The St. Petersburg-USA Orphanage Research Team (2008). The e $\square$ ects of early social-emotional and relationship experience on the development of young orphanage children. In W. A. Collins (Vol. Ed.), MONOGRAPHS of the society for RESEARCH in child development: 733.

Van IJzendoorn, M. H., Luijk, M., \& Ju $\square$ er, F. (2008). IQ of children growing up in children's homes: A meta-analysis on IQ delays in orphanages, MERRILL PALMER QUARTERLY, 54(3), 341-366.

Van IJzendoorn, M. H., Palacios, J., Sonuga-Barke, E., Gunnar, M., Vorria, P., ... Ju $\square$ er, F. (2011). Children in institutional care: Delayed development and resilience. MONOGRAPHS of the Society for RESEARCH in Child Development, 76(4), 8-30. https://doi.org/10.1111/j.1540-5834.2011.00626.x.

Vorria, P., Rutter, M., Pickles, A., Wolkind, S., \& Hobsbaum, A. (1998). A comparative study of Greek children in long-term residential group care and in two-parent families I: Social, emotional, and behavioral di $\square$ erences. JOURNAL of Child Psychology AND PSYCHIATRY, 39, 225-236.

Windsor, J., Benigno, J. P., Wing, C. A., Carroll, P. J., Koga, S. F., Nelson, C. A., \& Zeanah, C. A. (2011). E $\square$ ects of foster care on young children's language learning. Child Development, 82(4), 1040-1046. https://doi.org/10.1111/j.1467-8624.2011.01604.x.

Zeanah, C., Nelson, C. A., Fox, N. A., Smyke, A. T., Marshall, P., Parker, S. W., \& Koga, S. (2003). Designing research to study the e $\square$ ects of institutionalization on brain and behavioral development: The Bucharest Early Intervention Project. Development AND PSYCHOPATHOLOGY, 15(4), 885-907. 